\title{
The Respiratory System of Chromobacterium violaceum Grown under Conditions of High and Low Cyanide Evolution
}

\author{
By D. F. NIVEN, PAULINE A. COLLINS AND C. J. KNOWLES \\ Biological Laboratories, University of Kent, Canterbury $\mathrm{CT}_{2}{ }_{7} \mathrm{NJ}$
}

(Received 17 March I975; revised 5 April 1975)

\begin{abstract}
SUMMARY
The particulate fraction of disrupted Chromobacterium violaceum grown under cyanide-evolving conditions was unable to oxidize ascorbate plus $N, N, N^{\prime}, N^{\prime}$-tetramethyl-p-phenylenediamine (TMPD), but oxidized NADH and succinate by a linear respiratory pathway which was very resistant to inhibition by cyanide. When the bacteria were grown under conditions where little cyanide evolution occurred, particulate fractions developed the ability to oxidize ascorbate-TMPD by a pathway highly sensitive to cyanide inhibition; respiratory activity with NADH and succinate proceeded via both the cyanide-sensitive and -resistant pathways. Studies with respiratory inhibitors, and the cytochrome compositions of the fractions derived from cultures grown under both conditions, are presented. A soluble, carbon monoxide-binding cytochrome $c$ was found, and this appears similar to those found recently in Beneckea natriegens, methylotrophic bacteria and the marine pseudomonad Bi6.
\end{abstract}

\section{INTRODUCTION}

The respiratory systems of eukaryotic and prokaryotic organisms are usually highly sensitive to inhibition by cyanide (Gel'man, Lukoyanova \& Ostrovskii, 1967; Slater, 1967). In contrast, respiration in some plant and eukaryotic micro-organisms has been found to be cyanide insensitive (von Jagow \& Klingenberg, 1970; Bendall \& Bonner, 1971 ; Lambowitz \& Slayman, 1971; Ray \& Cross, 1972; Downie \& Garland, 1973). This is due to the presence of an 'alternate', cyanide-insensitive oxidase in addition to a normal cyanidesensitive cytochrome oxidase. The alternate oxidases may be inhibited specifically by hydroxamic acids (Schonbaum, Bonner, Storey \& Bahr, I97I). Oxidation of ascorbate plus $N, N, N^{\prime}, N^{\prime}$-tetramethyl-p-phenylenediamine (TMPD) occurs exclusively via the cyanidesensitive cytochrome oxidase.

Cyanide-resistant, aerobic respiration has been observed in several bacteria (Arima \& Oka, I965; Jones \& Redfearn, I967; McFeters, Wilson \& Strobel, I970; Weston, Collins \& Knowles, 1974). Respiratory branching occurs in Azotobacter vinelandii (Jones \& Redfearn, 1967; Ackrell \& Jones, 197I) and in Beneckea natriegens (Weston et al. 1974); in both cases one branch of the respiratory system is resistant to inhibition by cyanide.

We have investigated the respiratory system of Chromobacterium violaceum which evolves cyanide under certain growth conditions; in fact, cyanide production is a diagnostic test for this organism (Sneath, I966). This paper describes some of the properties of the respiratory system of $C$. violaceum grown under conditions where it evolves cyanide, and under conditions where little cyanide is produced. 


\section{METHODS}

Chromobacterium violaceum (strain D252, NCIB9I3I) was kindly supplied by Dr Dorothy Jones of the University of Leicester. The complex medium used consisted of $100 \mathrm{~mm}$ glycerol in nutrient broth $(25 \mathrm{~g}$ Oxoid dehydrated medium/1). The minimal medium consisted of $100 \mathrm{~mm}$-glycerol, M-9 salts (Miller, 1972) and I ml trace metal salts/1 (Bauchop \& Elsden, 1960). With both media $18 \mathrm{ml}$ of a stationary-phase culture were used to inoculate $900 \mathrm{ml}$ medium in a 21 conical flask; incubation was at $30^{\circ} \mathrm{C}$, in a gyrotary shaker $(200 \mathrm{rev}$. $\mathrm{min}$ ). Growth was allowed to proceed to the stationary phase ( $\mathrm{I} 6$ and $40 \mathrm{~h}$, on complex and minimal media respectively).

The bacteria were harvested by centrifugation at $2000 \mathrm{~g}$ for $20 \mathrm{~min}$. They were resuspended in $50 \mathrm{mM}-\mathrm{Na}_{2} \mathrm{HPO}_{4}-\mathrm{KH}_{2} \mathrm{PO}_{4}$ buffer, $\mathrm{pH} 7 \cdot 5$, recentrifuged (23000 $\mathrm{g}$, $10 \mathrm{~min}$ ) and resuspended in fresh buffer to about $250 \mathrm{mg}$ wet $\mathrm{wt} / \mathrm{ml}$. The bacteria were disrupted by sonication (MSE sonicator, $150 \mathrm{~W}$, for $4 \times \mathrm{I} \min$ at $0^{\circ} \mathrm{C}$ ) and, after centrifugation ( $12000 \mathrm{~g}, 10 \mathrm{~min}$ ) to remove the debris, were fractionated into particulate and supernatant fractions as described previously for $B$. natriegens (Weston \& Knowles 1973, 1974). The particulate fraction was resuspended in $50 \mathrm{mM}$-phosphate buffer $\mathrm{pH} \mathrm{7.5}$, at 20 to $60 \mathrm{mg}$ protein $/ \mathrm{ml}$.

Difference spectra of the cytochromes $\left(\mathrm{Na}_{2} \mathrm{~S}_{2} \mathrm{O}_{4}\right.$-reduced minus $\mathrm{H}_{2} \mathrm{O}_{2}$ - or ferricyanideoxidized, and $\mathrm{Na}_{2} \mathrm{~S}_{2} \mathrm{O}_{4}$-reduced-plus- $\mathrm{CO}$ minus $\mathrm{Na}_{2} \mathrm{~S}_{2} \mathrm{O}_{4}$-reduced) at both room and liquid nitrogen temperatures and pyridine haemochrome spectra of extracts and residues from acid-acetone treatment were determined as described by Weston \& Knowles (1973, 1974).

Respiration was measured at $30{ }^{\circ} \mathrm{C}$ with an oxygen electrode (Rank Bros, Bottisham, Cambridge). The incubation mixture contained up to $6 \mathrm{mg}$ particulate-fraction protein with $50 \mathrm{~mm}-\mathrm{Na}_{2} \mathrm{HPO}_{4}-\mathrm{NaH}_{2} \mathrm{PO}_{4}$ buffer, $\mathrm{pH} 7 \cdot 8$, in a total volume of $2 \cdot 9 \mathrm{ml}$. The reaction was initiated by the addition of $0.1 \mathrm{ml}$ substrate, to give final concentrations of $2.5 \mathrm{mM}$ $\mathrm{NADH}, 30 \mathrm{~mm}$-succinate and I.5 mM-ascorbate, plus either $\mathrm{I} \cdot 0 \mathrm{mM}-\mathrm{TMPD}, \mathrm{I} \cdot 0 \mathrm{~mm}-2,6-$ dichlorophenolindophenol (DCIP) or $0.5 \mathrm{~mm}$-horse heart cytochrome $c$. Water-insoluble inhibitors were added in $100 \mu \mathrm{l}$ dimethylformamide. An aqueous solution of $\mathrm{KCN}(\mathrm{pH} 7.8$ ) was freshly prepared for each experiment. The maximum concentrations of cyanide and azide used were 10 and $100 \mathrm{mM}$, respectively, as higher concentrations were found to alter the electrode response time.

Protein was assayed by the modified Biuret method of Gornall, Bardawill \& David (1949), and cyanide by the method of Epstein (1947). Bacterial growth was measured by the absorbance at $680 \mathrm{~nm}$ using $10 \mathrm{~mm}$ cuvettes in a SP500 spectrophotometer (PyeUnicam Ltd, Cambridge).

High-purity $\mathrm{CO}$ was obtained from the British Oxygen Co., London. 2-Heptyl-4-hydroxyquinoline- $N$-oxide (HOQNO), antimycin A, NADH (grade III), horse heart cytochrome $c$ (grade III) and DCIP were from Sigma. TMPD was obtained from Eastman Kodak Co., Liverpool, and salicylhydroxamic acid from Aldrich Chemical Co., Wembley, Middlesex. Whenever possible, all other reagents were of analytical grade; glass-distilled water was used throughout.

\section{RESULTS}

Growth and cyanide evolution

Chromobacterium violaceum grew well on both glycerol-nutrient broth complex medium and glycerol-minimal salts medium (Fig. 1). Growth on complex, but not minimal, medium was accompanied by the production of the pigment violacein (Sneath, 1966), which has a series of broad absorbance peaks throughout the visible region of the spectrum. This 


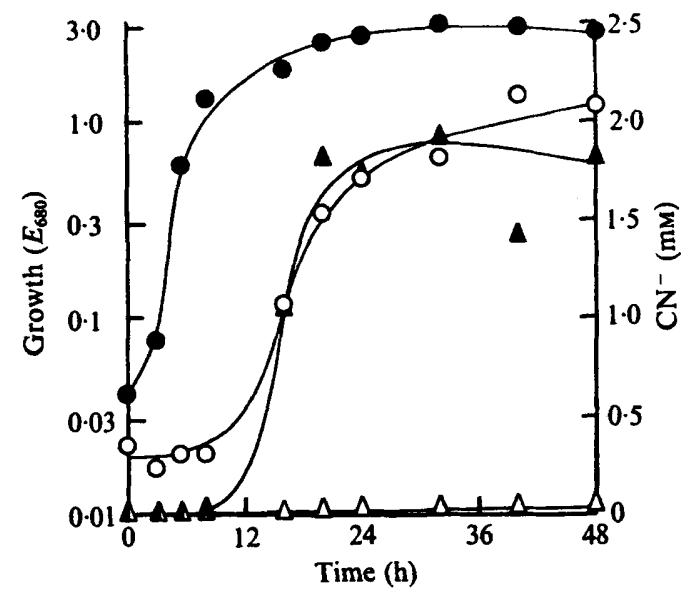

Fig. I. Growth curves and cyanide evolution for $C$. violaceum. Growth on complex (O) and minimal $(O)$ media was monitored at $680 \mathrm{~nm}$; cyanide evolution during growth on complex $(\Delta)$ and minimal $(\triangle)$ media was measured by the method of Epstein (1947).

Table I. Oxidase activities of the particulate fractions derived from cultures grown on complex and minimal media

\begin{tabular}{lcc} 
Substrate & \multicolumn{2}{c}{$\begin{array}{c}\text { Oxidase activity } \\
\text { (n-atoms oxygen uptake/min/mg protein) }\end{array}$} \\
\cline { 2 - 3 } & 130 & Minimal medium \\
NADH & 120 & 40 \\
Succinate & 6 & 300
\end{tabular}

resulted in a growth yield apparently greater than that on minimal medium, though in fact the cell yields using either medium were 3.5 to 4.0 wet wt/l.

On complex medium, vigorous cyanide evolution occurred during the late-exponential phase of growth (see Michaels \& Corpe, 1965), the concentration reaching a maximum of about $\mathrm{I} .8 \mathrm{mM}$ at the start of the stationary phase (Fig. I). Growth on minimal medium, however, was accompanied by little cyanide evolution (about $30 \mu \mathrm{M}$-cyanide by the onset of the stationary phase).

\section{Oxidase activities}

The particulate fractions derived from cultures grown on complex or minimal medium actively oxidized NADH and succinate (Table I), with higher activities in the particulate fraction of cultures from the complex medium. The particulate fraction of cultures from minimal medium oxidized ascorbate-TMPD at a high rate, but the particulate fraction of cultures from complex medium oxidized ascorbate-TMPD at only about $5 \%$ the rate of NADH and succinate oxidation. Ascorbate-DCIP and ascorbate-horse heart cytochrome $c$ were not oxidized by the particulate fraction of cultures from complex medium. Ascorbatehorse heart cytochrome $c$ was also not oxidized by the particulate fraction of cultures from minimal medium, but ascorbate-DCIP was oxidized at a similar rate to ascorbate-TMPD.

The supernatant fractions from cultures grown on both media possessed negligible NADH, succinate or ascorbate-TMPD oxidase activities. Addition of the supernatant fraction to the particulate fraction caused no stimulation of any of the oxidase activities. 

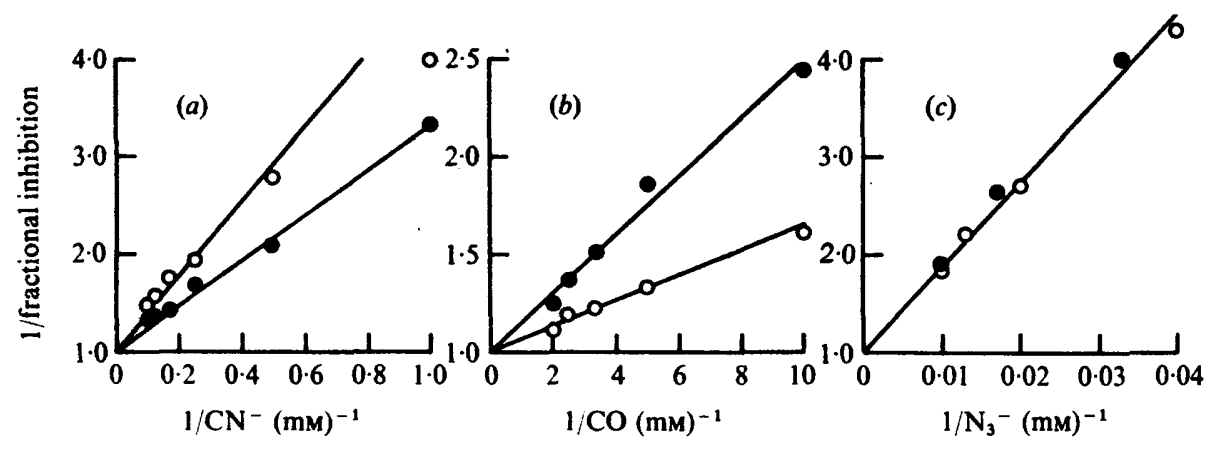

Fig. 2. Effect of cyanide, $\mathrm{CO}$ and azide on $\mathrm{NADH}$ and succinate oxidase activities of the particulate fraction from $C$. violaceum grown on complex medium. The reaction vessel contained, in $2.9 \mathrm{ml}$, particulate fraction and various concentrations of the inhibitors in $50 \mathrm{mM}$-sodium phosphate buffer $\mathrm{pH} 7.8$. The reactions were started by adding $0.1 \mathrm{ml}$ of either $75 \mathrm{~mm}-\mathrm{NADH}(\mathrm{O})$ or $900 \mathrm{~mm}-$ succinate (O). The incubation temperature was $30^{\circ} \mathrm{C}$.

We found it difficult to measure the oxidase activities of washed, intact bacteria utilizing exogenous substrates. In contrast to the highly reproducible oxidase activities found in extracts, extremely high and variable endogenous activities were found in intact bacteria which had been extensively washed and/or starved. Variability occurred between oxygen electrode experiments, even when using samples from the same batch of bacteria. We were therefore unable to measure the effectiveness of inhibitors with intact bacteria.

\section{Inhibitor studies}

Figure 2 shows the effects of cyanide, $\mathrm{CO}$ and azide on NADH and succinate oxidation by the particulate fraction of cultures from complex medium. Plots of the reciprocal of fractional inhibition against the reciprocal of inhibitor concentration for cyanide (Fig. $2 a$ ), carbon monoxide (Fig. $2 b$ ) and azide (Fig. $2 c$ ) all intercept the ordinate at $1 \cdot 0$, indicating that total inhibition may be effected at infinite concentrations of each of these inhibitors. However, respiration was very resistant to inhibition by all these compounds; for $50 \%$ inhibition, concentrations of the inhibitors were required $\mathrm{I}$ to 4 orders of magnitude greater than are typically needed to inhibit bacterial respiratory systems (but see Pudek \& Bragg, 1974). The rate of oxidation of ascorbate-TMPD was too low for effective inhibitor studies. Table 2 gives the concentrations of the inhibitors required for $50 \%\left(I_{0.5}\right)$ and $90 \%\left(I_{0.9}\right)$ inhibition of respiration, derived from the reciprocal plots.

Oxidation of ascorbate-TMPD by the particulate fraction of cultures grown on minimal medium was highly sensitive to inhibition by both cyanide (Fig. 3) and azide (Fig. 4). With both inhibitors, reciprocal plots intercepted the ordinate at $1 \cdot 0$, indicating $100 \%$ inhibition at infinite inhibitor concentrations (Figs. $3 c, 4) ; I_{0 \cdot 5}$ and $I_{0.9}$ values are given in Table 2. When the rate of respiration of ascorbate-TMPD was lowered to less than $10 \%$ of maximal activity by reducing the TMPD concentration, similar concentrations of cyanide or azide were still required for $90 \%$ inhibition (see Pudek \& Bragg, 1974).

Oxidation of NADH and succinate by the particulate fraction of cultures grown on minimal medium was inhibited in a biphasic manner by both cyanide and azide. Low concentrations of these inhibitors caused partial inhibition of activity; much higher concentrations were required for substantial inhibition to be effected, the two phases being separated by a 'plateau' region (e.g. Fig. $3 a, b$ ). These inhibition curves are similar to those reported recently for $B$. natriegens (Weston et al. 1974). 


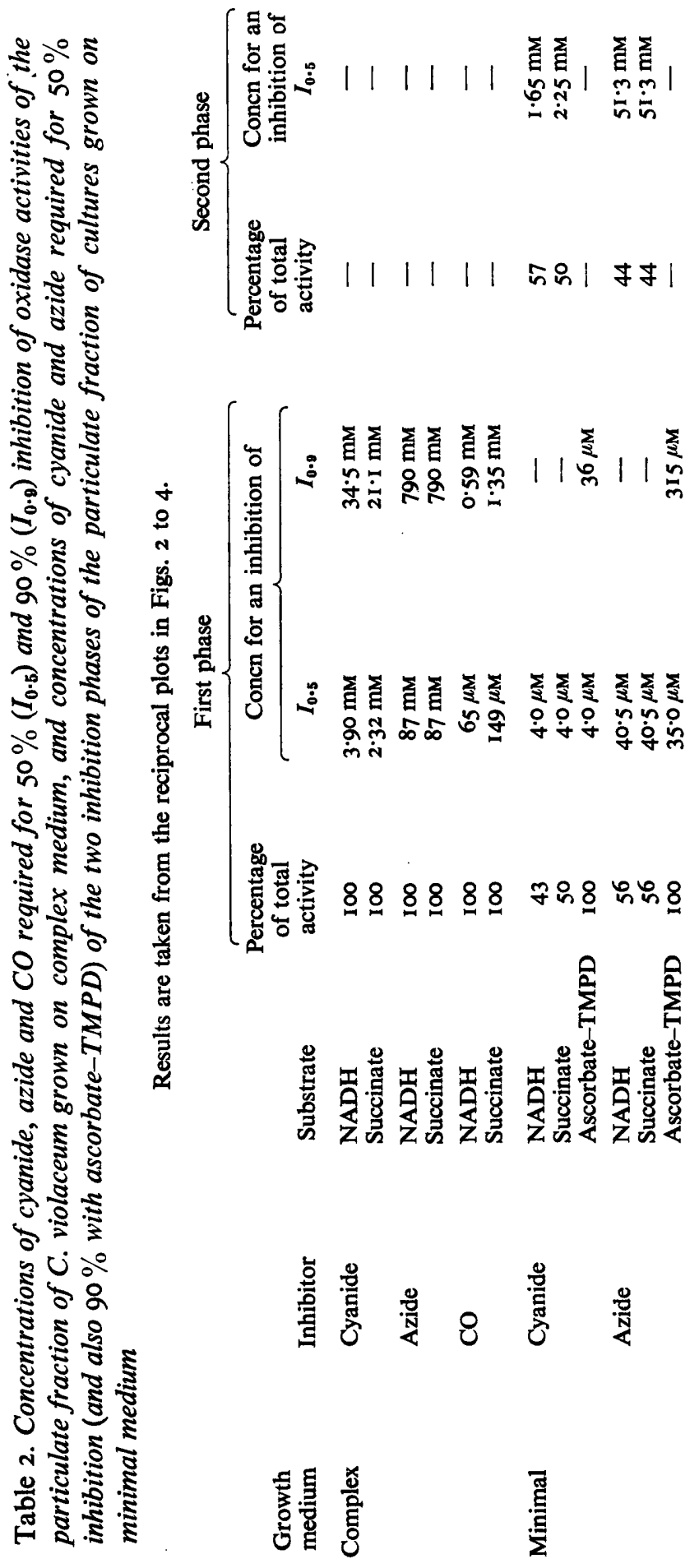



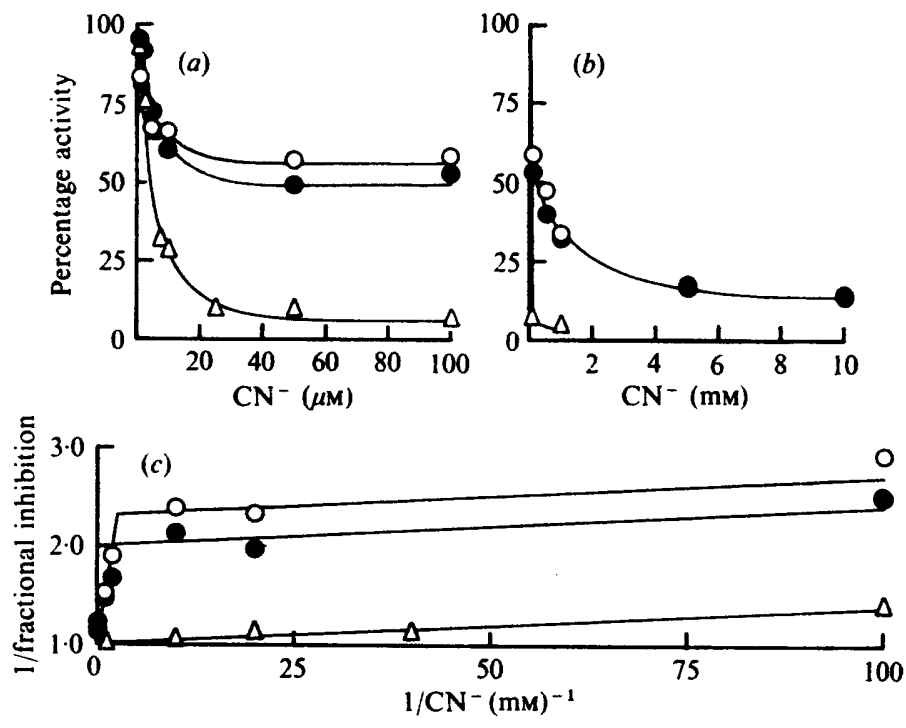

Fig. 3. Effect of cyanide on NADH, succinate and ascorbate-TMPD oxidase activities of the particulate fraction from $C$. violaceum grown on minimal medium. The reaction vessel contained, in $2.9 \mathrm{ml}$, particulate fraction and various concentrations of cyanide in $50 \mathrm{~mm}$-sodium phosphate buffer $\mathrm{pH} \mathrm{7 \cdot 8}$. The reactions were started by adding $0 . \mathrm{I} \mathrm{ml}$ of either $75 \mathrm{mM}-\mathrm{NADH}(\mathrm{O})$ or $900 \mathrm{mM}-$ succinate (O), or by adding $0.05 \mathrm{ml} 90 \mathrm{~mm}$-ascorbate followed by $0.05 \mathrm{ml} 60 \mathrm{mM}-\mathrm{TMPD}(\triangle)$. The incubation temperature was $30^{\circ} \mathrm{C}$.

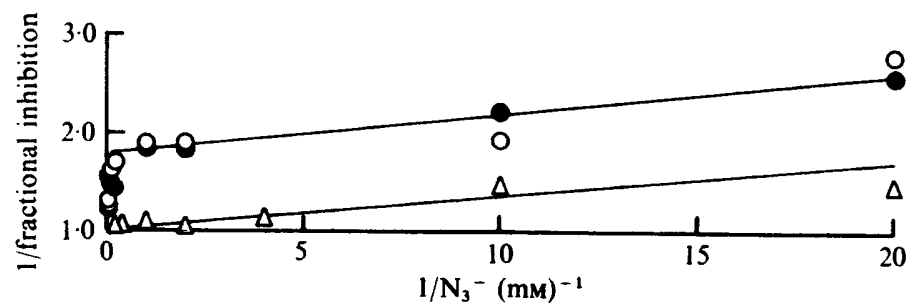

Fig. 4. Effect of azide on NADH, succinate and ascorbate-TMPD oxidase activities of the particulate fraction from $C$. violaceum grown on minimal medium. The reaction vessel contained, in $2.9 \mathrm{ml}$, particulate fraction and various concentrations of azide in $50 \mathrm{~mm}$-sodium phosphate buffer pH $7 \cdot 8$. The reactions were started by adding $0.1 \mathrm{ml}$ of either $75 \mathrm{Mm}-\mathrm{NADH}(\mathrm{O})$ or $900 \mathrm{~mm}$-succinate $(\Theta)$, or by adding $0.05 \mathrm{ml} 90 \mathrm{~mm}$-ascorbate followed by $0.05 \mathrm{ml} 60 \mathrm{mM}$-TMPD $(\triangle)$. The incubation temperature was $30^{\circ} \mathrm{C}$.

Double reciprocal plots of the inhibition of NADH and succinate oxidases by cyanide and azide (Figs. $3 c$ and 4 ) were also biphasic. Analysis of the reciprocal plots shows that the phase more sensitive to inhibition is $50 \%$ inhibited by similar concentrations of cyanide and azide to those required for $50 \%$ inhibition $\left(I_{0.5}\right)$ of ascorbate-TMPD oxidation (Table 2$)$. The less sensitive phase is $50 \%$ inhibited by concentrations of cyanide and azide similar to those required for $50 \%$ inhibition $\left(I_{0 \cdot 5}\right)$ of oxidation of NADH and succinate by the particulate fraction of cultures grown on complex medium (Table 2).

Oxidation of NADH, succinate or ascorbate-TMPD by the particulate fraction of cultures grown on minimal medium was resistant to inhibition by $\mathrm{CO} ; 0.5 \mathrm{mM}$-CO caused less than $30 \%$ inhibition of all three oxidases, ascorbate-TMPD oxidation being slightly less inhibited than NADH or succinate. 

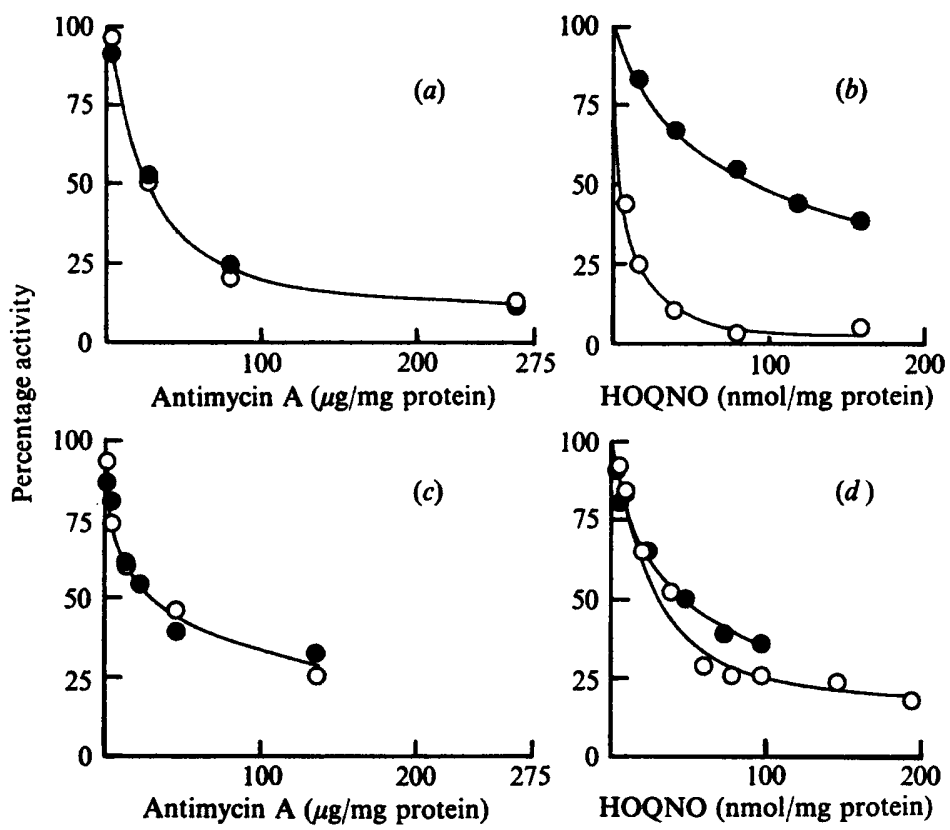

Fig. 5. Effect of antimycin A and HOQNO on NADH and succinate oxidase activities of the particulate fractions from $C$. violaceum grown on complex and minimal media. The reaction vessel contained, in $2.9 \mathrm{ml}$, particulate fraction from either bacteria grown on complex $(a, b)$ or minimal $(c, d)$ media, various concentrations of the inhibitors in $0.1 \mathrm{ml}$ dimethylformamide, and $50 \mathrm{~mm}$ sodium phosphate buffer $\mathrm{pH} 7 \cdot 8$. The reactions were started by adding $0 \cdot 1 \mathrm{ml}$ of either $75 \mathrm{mM}$ NADH (O) or $900 \mathrm{~mm}$-succinate (O). The incubation temperature was $30^{\circ} \mathrm{C}$.

Oxidation of NADH or succinate by the particulate fractions of cultures of bacteria grown on both media was inhibited by both antimycin A and HOQNO (Fig. 5). These two substrates had a similar sensitivity to antimycin A, irrespective of growth conditions. However, for HOQNO inhibition, NADH oxidase was more sensitive than succinate oxidase, and the difference between the two was greater for the particulate fraction of cultures grown on complex medium than for the particulate fraction of cultures grown on minimal medium. These results suggest that antimycin $A$ and HOQNO act either at different sites, or at the same site with HOQNO having a further site of action on the pathway of NADH oxidation, possibly in the dehydrogenase region. As expected, antimycin A and HOQNO had no effect on ascorbate-TMPD oxidation by the particulate fraction of cultures grown on minimal medium.

\section{Cytochrome composition}

Room-temperature reduced minus oxidized difference spectra of the particulate fraction of $C$. violaceum grown on complex medium had peaks at $55^{2}$ and $523 \mathrm{~nm}$ corresponding to a $c$-type cytochrome, with shoulders at 559 and $528 \mathrm{~nm}$ due to a $b$-type cytochrome. In addition, there were peaks at 623 to $628 \mathrm{~nm}$ (cytochrome $d$ ) and at 595 to $600 \mathrm{~nm}$ (cytochrome $a_{1}$ ). The Soret peak at $429 \mathrm{~nm}$, due to the fused $\gamma$-peaks of the $b$ - and $c$-type cytochromes, had a shoulder at $438 \mathrm{~nm}$ due to $a$-type cytochromes.

The spectra were considerably sharpened when measured at $77^{\circ} \mathrm{K}$ in $0.8 \mathrm{M}$-sucrose (Fig. 6); in particular, there were separate peaks at 556 and $528 \mathrm{~nm}$ due to the $b$-type cytochromes. All peaks were shifted 2 to $3 \mathrm{~nm}$ towards the ultraviolet region. The Soret peak was at $423 \mathrm{~nm}$ and had a shoulder at $440 \mathrm{~nm}$ due to cytochrome $a_{1}$ (not shown). 


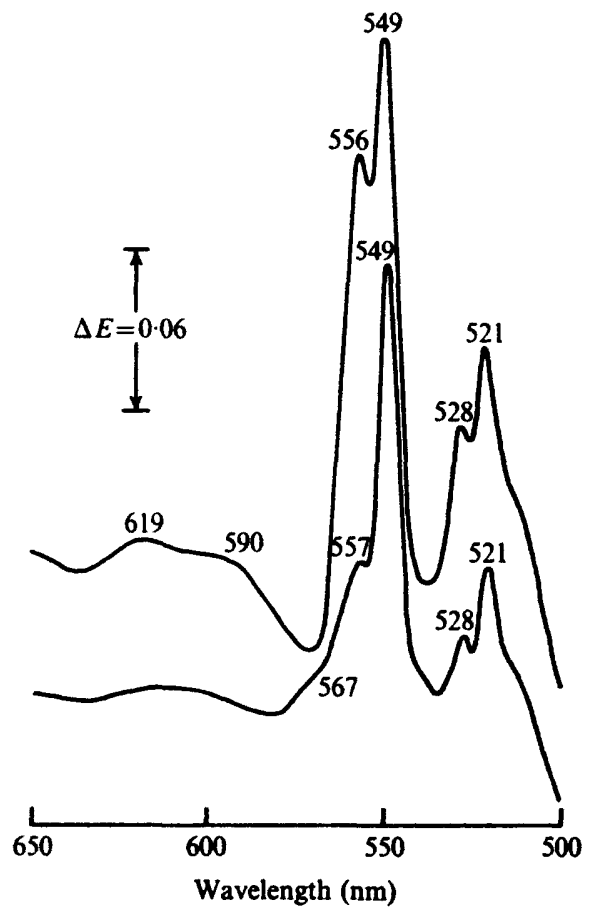

Fig. 6

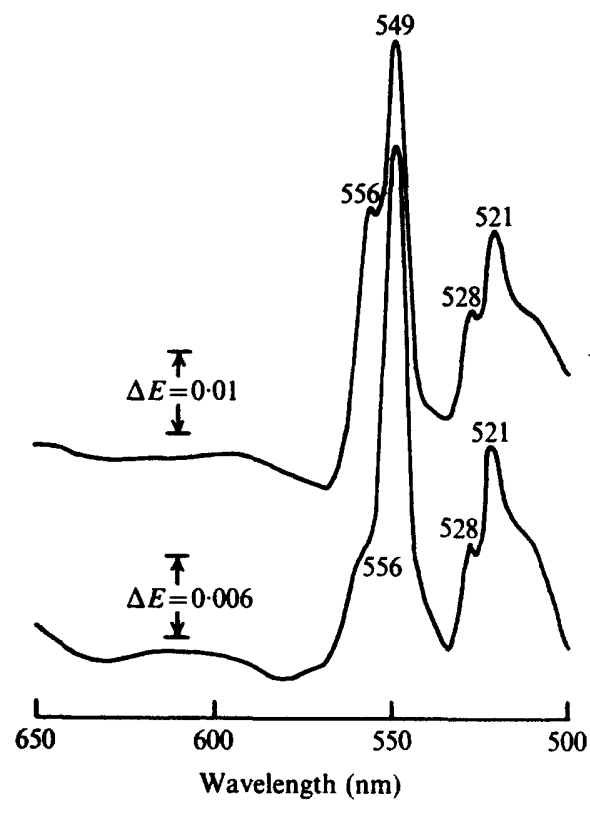

Fig. 7

Fig. 6. $\mathrm{Na}_{2} \mathrm{~S}_{2} \mathrm{O}_{4}$-reduced minus $\mathrm{K}_{9} \mathrm{Fe}(\mathrm{CN})_{6}$-oxidized difference spectra of the particulate and supernatant fractions from $C$. violaceum grown on complex medium. Particulate fraction $(5 \mathrm{mg}$ protein $/ \mathrm{ml}$ ) or supernatant fraction $(8 \mathrm{mg}$ protein $/ \mathrm{ml})$ were suspended in $50 \mathrm{~mm}$-sodium/potassium phosphate buffer pH 7.5, containing $0.8 \mathrm{M}$-sucrose; addition of a few grains of either $\mathrm{Na}_{2} \mathrm{~S}_{2} \mathrm{O}_{4}$ or $\mathrm{K}_{3} \mathrm{Fe}(\mathrm{CN})_{6}$ was used to reduce or oxidize the fractions. The light path was $2 \mathrm{~mm}$ and the temperature $77^{\circ} \mathrm{K}$. Upper line, particulate fraction; lower line, supernatant fraction.

Fig. 7. $\mathrm{Na}_{2} \mathrm{~S}_{2} \mathrm{O}_{4}$-reduced minus $\mathrm{K}_{8} \mathrm{Fe}(\mathrm{CN})_{6}$-oxidized difference spectra of the particulate and supernatant fractions from $C$. violaceum grown on minimal medium. Particulate fraction ( $2 \mathrm{mg}$ protein $/ \mathrm{ml}$ ) or supernatant fraction $(4.8 \mathrm{mg}$ protein $/ \mathrm{ml}$ ) was suspended in $50 \mathrm{~mm}$-sodium/potassium phosphate buffer, $\mathrm{pH} \mathrm{7.5}$, containing $0.8 \mathrm{M}$-sucrose; addition of a few grains of either $\mathrm{Na}_{2} \mathrm{~S}_{2} \mathrm{O}_{4}$ or $\mathrm{K}_{3} \mathrm{Fe}(\mathrm{CN})_{6}$ was used to reduce or oxidize the fractions. The light path was $2 \mathrm{~mm}$ and the temperature $77^{\circ} \mathrm{K}$. Upper line, particulate fraction; lower line, supernatant fraction.

Room-temperature reduced minus oxidized difference spectra of the supernatant fractions of cultures grown on complex medium had peaks at $55 \mathrm{I}$ and $523 \mathrm{~nm}$ due to a $c$-type cytochrome, with rather indistinct shoulders at 559 and $528 \mathrm{~nm}$ due to a small quantity of $b$-type cytochrome. The Soret peak was at $427 \mathrm{~nm}$, with a small shoulder at 436 to $437 \mathrm{~nm}$. When measured in $0.8 \mathrm{M}$-sucrose at $77^{\circ} \mathrm{K}$ (Fig. 6), the $\alpha$ - and $\beta$-peaks of the cytochrome $c$ shifted to 549 and $52 \mathrm{I} \mathrm{nm}$, whilst there were distinct, but smaller, peaks at 557 and $528 \mathrm{~nm}$ due to lower concentrations of cytochrome $b$. Also present was a small shoulder at $567 \mathrm{~nm}$ due to an unidentified component. In the Soret region (not shown), there was a peak at $424 \mathrm{~nm}$ and a shoulder at $436 \mathrm{~nm}$.

Pyridine-haemochrome spectra of acid-acetone extracts and residues from the particulate fraction of cultures grown on complex medium indicate that similar concentrations of $b$ - and $c$-type cytochromes were present (not shown). However, pyridine-haemochrome spectra of the supernatant fraction indicate that the $b$-type cytochrome was present at only about $15 \%$ of the $c$-type cytochrome in this fraction. This value is less than the relative 


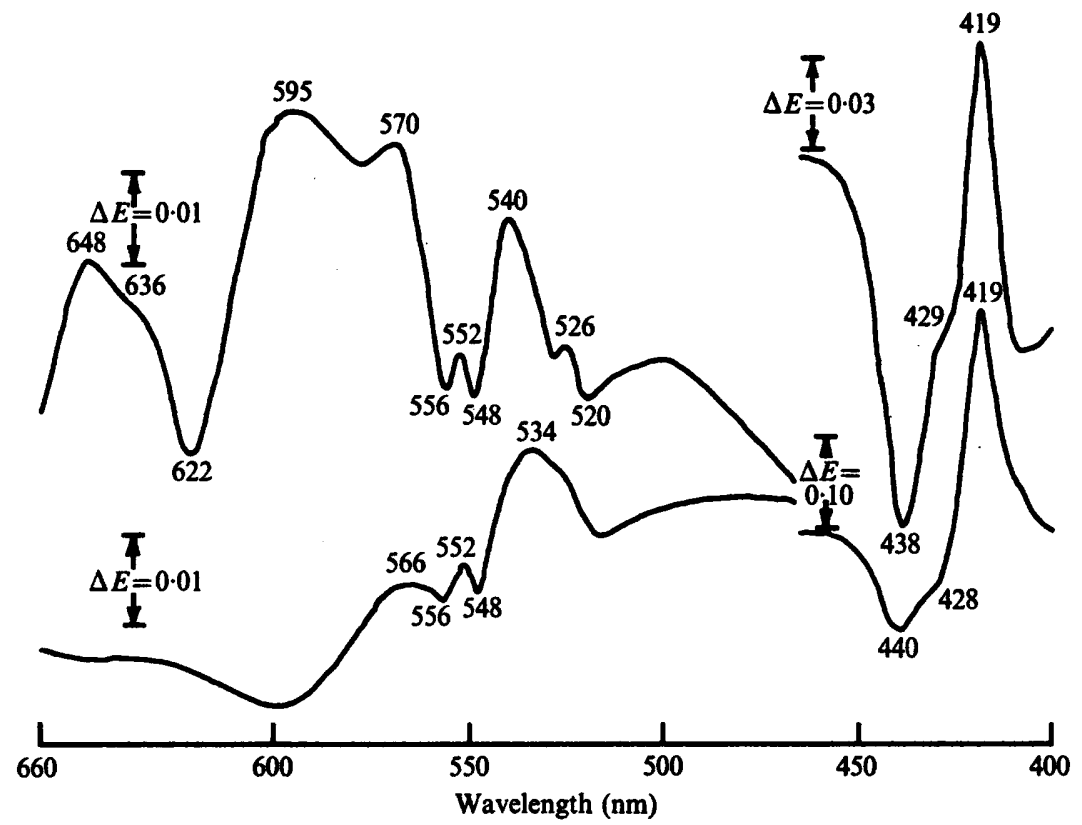

Fig. 8. $\mathrm{Na}_{2} \mathrm{~S}_{2} \mathrm{O}_{4}$-reduced-plus-CO minus $\mathrm{Na}_{2} \mathrm{~S}_{2} \mathrm{O}_{4}$-reduced difference spectra of the particulate and supernatant fractions from $C$. violaceum grown on complex medium. Particulate fraction at $5 \mathrm{mg}$ protein $/ \mathrm{ml}$ (visible region) or $2.5 \mathrm{mg}$ protein per ml (Soret region), or supernatant fraction $(8 \mathrm{mg}$ protein $/ \mathrm{ml})$ was suspended in $50 \mathrm{~mm}$-sodium/potassium phosphate buffer $\mathrm{pH} 7.5$ containing $0.8 \mathrm{M}$-sucrose, and reduced by the addition of a few grains of $\mathrm{Na}_{2} \mathrm{~S}_{2} \mathrm{O}_{4}$. CO treatment was by bubbling for I min followed by $10 \mathrm{~min}$ incubation before freezing to $77^{\circ} \mathrm{K}$ and recording. The cuvette light path was $2 \mathrm{~mm}$. Upper lines, particulate fraction; lower lines, supernatant fraction.

concentration of cytochrome $b$ to cytochrome $c$ estimated from the cytochrome $\alpha$-peaks in reduced minus oxidized difference spectra (Fig. 6 and Table 3 ). This was probably due to overlap of the cytochrome $b$ peak in the difference spectra by the dominant cytochrome $c$ peak.

Room-temperature reduced-plus-CO minus reduced difference spectra of the particulate fraction of bacteria grown on complex medium had a peak at $420 \mathrm{~nm}$, a shoulder at $429 \mathrm{~nm}$ and a trough at $44 \mathrm{I} \mathrm{nm}$ in the Soret region; there were also a series of indistinct peaks and troughs in the visible region. When the spectra were measured at $77^{\circ} \mathrm{K}$ in $0.8 \mathrm{M}$-sucrose, the Soret peak was at $419 \mathrm{~nm}$, with a large shoulder at 428 to $429 \mathrm{~nm}$ and a trough at $438 \mathrm{~nm}$ (Fig. 8). In the visible region, there was a series of distinct peaks and troughs. The peak at $636 \mathrm{~nm}$ corresponded to cytochrome $d$ and the peak at $595 \mathrm{~nm}$ (plus the shoulder at 428 to $429 \mathrm{~nm}$ on the Soret peak) was due to cytochrome $a_{1}$. The W-shaped curve in the 570 to $540 \mathrm{~nm}$ region was presumably due to two components with overlapping peaks, possibly two o-type (protohaem) cytochromes or, alternatively, an o-type (trough at $556 \mathrm{~nm}$ ) plus a CO-binding $c$-type $\left(c_{\mathrm{co}}\right)$ cytochrome (trough at $548 \mathrm{~nm}$ ) (see Daniel, 1970; Weston \& Knowles, I973). The Soret peak at $419 \mathrm{~nm}$ was due to the fused $\gamma$-peaks of these components. The nature of the $648 \mathrm{~nm}$ absorbing component is not known.

Room-temperature reduced-plus-CO minus reduced difference spectra of the supernatant fraction of cultures grown on complex medium had a peak at $4 \mathrm{I} 9 \mathrm{~nm}$ and a trough at $436 \mathrm{~nm}$, with an indistinct trough at about $549 \mathrm{~nm}$. When measured at $77^{\circ} \mathrm{K}$ in $0.8 \mathrm{M}-$ sucrose, the Soret peak was at $419 \mathrm{~nm}$, with a very small shoulder at $428 \mathrm{~nm}$ (Fig. 8). In the 
Table 3. Distribution of total and $\mathrm{CO}$-binding cytochromes of the particulate and supernatant fractions of $C$. violaceum grown on complex and minimal media

\begin{tabular}{|c|c|c|c|c|c|c|c|c|c|}
\hline \multirow[b]{3}{*}{$\begin{array}{l}\text { Growth } \\
\text { medium }\end{array}$} & \multirow[b]{3}{*}{$\begin{array}{c}\text { Cell } \\
\text { fraction }\end{array}$} & & & & & \multicolumn{4}{|c|}{$\begin{array}{l}\text { CO-binding cytochrome } \\
\text { (pmol/mg protein) }\end{array}$} \\
\hline & & \multicolumn{4}{|c|}{$\begin{array}{l}\text { Total cytochrome } \\
\text { (pmol/mg protein) }\end{array}$} & \multicolumn{2}{|c|}{$\begin{array}{l}\text { Component } \\
\text { with } 419 \mathrm{~nm} \\
\text { Soret peak } \\
\text { estimated as: }\end{array}$} & \multicolumn{2}{|c|}{$\begin{array}{c}\text { Other } \\
\text { CO-binding } \\
\text { cytochromes }\end{array}$} \\
\hline & & cyt. $b$ & cyt. $c$ & cyt. $a$ & ${ }_{1}$ cyt. $d$ & cyt. $o$ & $\overbrace{\text { cyt. } c_{\mathrm{Co}}}$ & $\overbrace{\text { cyt. } a_{1}}$ & $\underset{\text { cyt. } d}{ }$ \\
\hline \multirow[t]{2}{*}{ Complex } & Particulate & 616 & 647 & + & + & 52 & 80 & + & + \\
\hline & Supernatant & 53 & 202 & - & - & 194 & 300 & - & - \\
\hline \multirow{2}{*}{ Minimal } & Particulate & 504 & 784 & - & - & I I 6 & 180 & - & - \\
\hline & Supernatant & 67 & 319 & - & - & 164 & 254 & - & - \\
\hline
\end{tabular}

The total concentrations of cytochromes $b$ and $c$ were determined from room temperature $\mathrm{Na}_{2} \mathrm{~S}_{2} \mathrm{O}_{4}$ reduced minus $\mathrm{K}_{3} \mathrm{Fe}(\mathrm{CN})_{6}$-oxidized difference spectra using the extinction coefficients given by Jones \& Redfearn (1966). The concentrations of cytochromes $a_{1}$ and $d$ were too low for accurate determination; + indicates their presence and - their absence. The CO-binding components with Soret peaks at about $419 \mathrm{~nm}$ were determined from their 'peak to plateau' absorbance and estimated as cytochrome $o$ or cytochrome $c_{C o}$ from room temperature $\mathrm{Na}_{2} \mathrm{~S}_{2} \mathrm{O}_{4}$-reduced-plus-CO minus $\mathrm{Na}_{2} \mathrm{~S}_{2} \mathrm{O}_{4}$-reduced difference spectra using the extinct!on coefficients given by Chance (1961) and Bartsch (1967) ( $\mathrm{E}_{\mathrm{mm}}=85$ or $55 /$ haem group, respectively). Note that the concentrations of total cytochromes $b$ in the supernatant fractions may be overestimated due to peak overlap (see text).

visible region, there were peaks at 566,552 and, especially, at $534 \mathrm{~nm}$, and troughs at 556 and $548 \mathrm{~nm}$. Like the particulate fraction, the complex curve in the 540 to $570 \mathrm{~nm}$ region and the Soret peak at $4 \mathrm{I} 9 \mathrm{~nm}$ were probably due to cytochrome(s) $o$ and/or $c_{\mathrm{co}}$. The much greater absorbance at $534 \mathrm{~nm}$ than at $566 \mathrm{~nm}$ would suggest that the component with the trough at $548 \mathrm{~nm}$ was present at a higher concentration than the other component. There are no peaks in the 570 to $650 \mathrm{~nm}$ region due to $a$ - or $d$-type cytochromes.

The total concentrations of the cytochromes in the particulate and supernatant fractions derived from bacteria grown on complex medium were estimated from reduced minus oxidized difference spectra using published extinction coefficients (Table 3). Similarly, the concentration of the CO-binding cytochrome(s) with a Soret peak at about $420 \mathrm{~nm}$ was estimated by assuming that it is either a cytochrome $o$ ('peak-to-plateau' $E_{\mathrm{mm}}=85 / \mathrm{haem}$ group; Chance, 196I) or a CO-binding cytochrome $c\left(E_{\mathrm{mx}}=55 /\right.$ haem group; Bartsch, 1967). Even taking into account possible peak overlap and partial enhancement or cancellation of the peak, as well as errors in the assumed extinction coefficients, it is clear that the $\mathrm{CO}$ binding of the supernatant fraction was due principally to $\mathrm{CO}$ binding by the cytochrome $c$, as there was insufficient total cytochrome $b$ present to account for the observed extent of $\mathrm{CO}$ binding. The trough at $548 \mathrm{~nm}$ in the low-temperature $\mathrm{CO}$ spectra (Fig. 8) was therefore most probably due to CO-binding cytochrome $c$, whilst the trough at $556 \mathrm{~nm}$ could have been due to lower concentrations of cytochrome $o$.

Room-temperature reduced minus oxidized difference spectra of the particulate fraction of cultures grown on minimal medium had peaks at 552 and $523 \mathrm{~nm}$ due to cytochrome $c$, and shoulders at 559 and $529 \mathrm{~nm}$ due to cytochrome $b$; the Soret peak at $427 \mathrm{~nm}$ had an exceedingly small shoulder at $439 \mathrm{~nm}$. In low temperature spectra, the shoulders due to cytochrome $b$ were resolved as separate peaks at 556 and $528 \mathrm{~nm}$ (Fig. 7). The Soret peak at $426 \mathrm{~nm}$ (not shown) had a very small shoulder at $438 \mathrm{~nm}$; there were no discernible peaks in the 580 to $650 \mathrm{~nm}$ region, indicating the almost complete absence (cf. shoulder at 


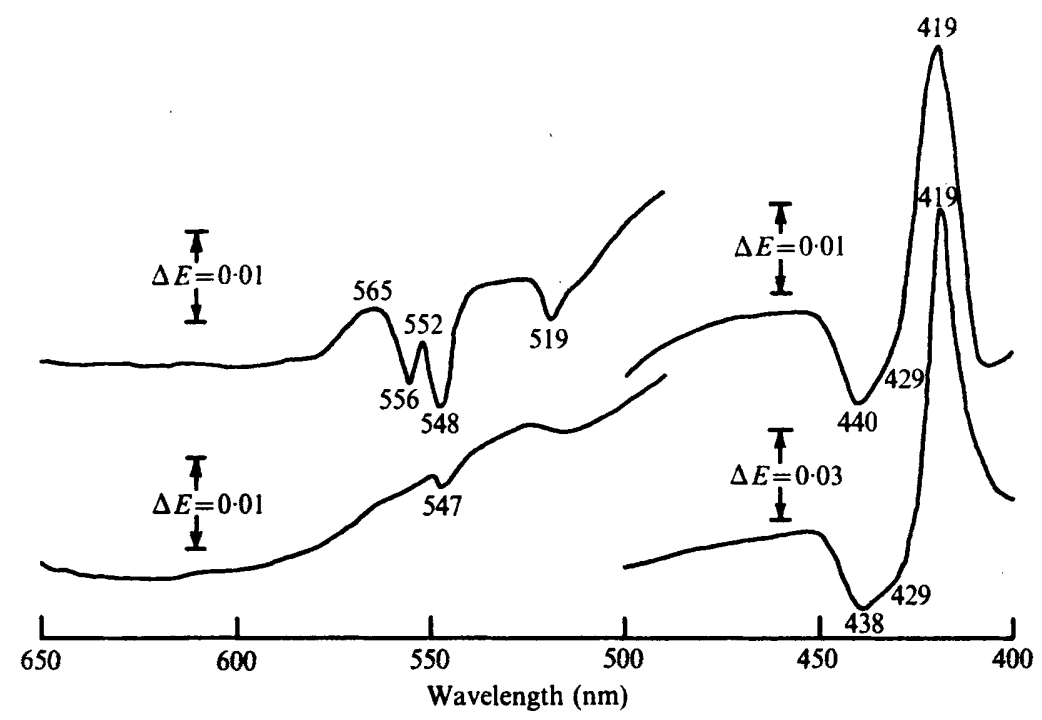

Fig. 9. $\mathrm{Na}_{2} \mathrm{~S}_{2} \mathrm{O}_{4}$-reduced-plus-CO minus $\mathrm{Na}_{2} \mathrm{~S}_{2} \mathrm{O}_{4}$-reduced difference spectra of the particulate and supernatant fractions from $C$. violaceum grown on minimal medium. Particulate fraction $(7 \cdot 7 \mathrm{mg}$ protein $/ \mathrm{ml}$ ) or supernatant fraction $(4.5 \mathrm{mg}$ protein $/ \mathrm{ml}$ ) was suspended in $50 \mathrm{~mm}$-sodium/potassium phosphate buffer $\mathrm{pH} \mathrm{7.5}$, containing $0.8 \mathrm{M}$-sucrose, and reduced by the addition of a few grains of $\mathrm{Na}_{2} \mathrm{~S}_{2} \mathrm{O}_{4}$. CO treatment was by bubbling for 1 min followed by $10 \mathrm{~min}$ incubation before freezing to $77^{\circ} \mathrm{K}$ and recording. The cuvette light path was $2 \mathrm{~mm}$. Upper lines, particulate fraction; lower lines, supernatant fraction.

$438 \mathrm{~nm}$ ) of $a$ - or $d$-type cytochromes. The relative concentration of cytochrome $c$ to cytochrome $b$ (Table 3) was greater than that found for the particulate fraction of cultures grown on complex medium.

Room-temperature reduced minus oxidized difference spectra of the supernatant fraction of cultures grown on minimal medium had peaks at $55 \mathrm{I}$ and $523 \mathrm{~nm}$ due to cytochrome $c$, and rather indistinct shoulders at 559 and $529 \mathrm{~nm}$ due to a small quantity of cytochrome $b$; the Soret peak was at $426 \mathrm{~nm}$ with a small shoulder at $436 \mathrm{~nm}$. In low-temperature spectra the visible-region peaks were shifted 2 to $3 \mathrm{~nm}$ towards the ultraviolet region (Fig. 7), and in addition a small but distinct shoulder was seen at $556 \mathrm{~nm}$, which was due to the presence of some cytochrome $b$; the Soret peak at $422 \mathrm{~nm}$ (not shown) had a shoulder at $435 \mathrm{~nm}$.

Room-temperature reduced-plus- $\mathrm{CO}$ minus reduced difference spectra of the particulate fraction of cultures grown on minimal medium had an indistinct trough in the visible region at about $556 \mathrm{~nm}$, with a shoulder at $550 \mathrm{~nm}$. In the Soret region, there was a trough at 44I $\mathrm{nm}$ and a peak at $420 \mathrm{~nm}$. In spectra at the temperature of liquid nitrogen, the Soret peak was at $419 \mathrm{~nm}$ and the visible region trough was resolved into two components with minima at 556 and $548 \mathrm{~nm}$ (Fig. 9). Unlike the particulate fraction of cultures grown on complex medium, there were no peaks in the 580 to $650 \mathrm{~nm}$ region, and only a very small shoulder at $429 \mathrm{~nm}$ on the Soret peak, which confirms the almost complete absence of $a$ - and $d$-type cytochromes, as noted in the reduced minus oxidized difference spectra (Fig. 7).

Room-temperature reduced-plus- $\mathrm{CO}$ minus reduced difference spectra of the supernatant fraction of cultures grown on minimal medium had troughs at 55I and $437 \mathrm{~nm}$ and a Soret peak at $419 \mathrm{~nm}$. At low temperatures, the visible-region trough was at $547 \mathrm{~nm}$ and the Soret peak, which possessed an exceedingly small shoulder at $429 \mathrm{~nm}$, was at $419 \mathrm{~nm}$ (Fig. 9). No extra bands were observed, unlike the low-temperature CO spectra of the supernatant 
fraction of cultures grown on complex medium, where a small trough at $556 \mathrm{~nm}$ was resolved (Fig. 8). This could have been due to an absence of cytochrome $o$, or a much lower relative concentration of it such that it was not spectrally resolved, in the supernatant fraction of cultures grown on minimal medium. Analysis of the total concentrations of cytochromes $b$ and $c$ relative to the CO-binding cytochrome (Table 3 ) indicated that there was too little cytochrome $b$ to account for the $\mathrm{CO}$ binding which must, as expected from the position of the visible-region troughs, have been due principally to $\mathrm{CO}$ binding by the $c$-type cytochrome.

\section{DISCUSSION}

Respiratory resistance to cyanide inhibition may be induced in Achromobacter (Arima \& Oka, 1965) and Bacillus cereus (McFeters et al. 1970) by growth in the presence of cyanide. In both organisms, induction of cyanide resistance is accompanied by an increase in the concentration of cytochrome $d$ (Arima \& Oka, 1965; Niven and Knowles, unpublished observations); cytochrome $d$ may be the cyanide-resistant oxidase. Unfortunately these papers give no evidence for the exact pathways of electron flow in Achromobacter or Bac. cereus.

On the other hand, cyanide-resistant respiration occurs in $A$. vinelandii (Jones \& Redfearn, 1966; Ackrell \& Jones, 197I) and B. natriegens (Weston et al. 1974), despite growth in the absence of cyanide. In both organisms, respiration occurs via a terminally branched respiratory system, with one branch sensitive to cyanide and the other resistant. Ascorbate-TMPD or ascorbate-DCIP oxidation occurs exclusively via the cyanide-sensitive pathway; a similar situation prevails in branched mitochondrial respiratory systems (e.g. Lambowitz \& Slayman, 1971).

Growth of $C$. violaceum under cyanide-synthesizing and -evolving conditions might therefore be expected to result in the development of a respiratory system that is resistant to cyanide and perhaps other inhibitors of cytochrome oxidase (azide and $\mathrm{CO}$ ). Furthermore, since ascorbate-TMPD oxidation usually occurs via a cyanide-sensitive oxidase, it would also seem likely that such a pathway would not be induced under these conditions. This is found to be the case, since ascorbate-TMPD oxidase activity was negligible (Table I) and respiration of NADH and succinate was highly resistant to inhibition by cyanide, azide and $\mathrm{CO}$ (Fig. 2). Analysis of the inhibition curves show that, at infinite inhibitor concentrations, total inhibition of oxidation occurs (Fig. 2) and the monophasic, double-reciprocal plots suggest that a conventional, linear respiratory pathway is operative. Despite the resistance to inhibition by cyanide, azide and $\mathrm{CO}$, the oxidation of NADH and succinate is respiratory-linked, as their oxidation is sensitive to inhibition by antimycin A and HOQNO.

The particulate fraction of cultures grown on minimal medium actively oxidizes ascorbateTMPD. This activity is highly sensitive to inhibition by cyanide and azide (Figs. 3 and 4) but uninhibited by $\mathrm{CO}$. In addition, cyanide and azide inhibition curves for NADH and succinate are no longer monophasic, but have inhibitor-sensitive and -insensitive components (Figs. 3, 4). The inhibitor-resistant component displays a degree of resistance similar to that found for the inhibition of NADH and succinate oxidation by the particulate fraction of bacteria grown on complex medium (Table 2), suggesting that this component is common to organisms grown under both conditions.

The simplest interpretation of these results is that terminal branching of the respiratory system occurs, with one pathway resistant to cyanide and azide inhibition and the other sensitive. Oxidation of ascorbate-TMPD would then occur exclusively via the latter pathway. Branching also occurs after the site(s) of antimycin A and HOQNO inhibition (Fig. 5). 
This interpretation is in agreement with the previously observed respiratory branching in extracts of $A$. vinelandii (Jones \& Redfearn, 1967) and $B$. natriegens (Weston et al. I974).

An alternative explanation could be that there are two parallel pathways of oxidation of NADH and succinate, one sensitive to cyanide and azide inhibition (with associated ascorbate-TMPD oxidase activity) and the other more resistant to their inhibitory action. However, such an interpretation would require excessive synthesis of dehydrogenases, etc., and being unnecessarily wasteful of the cell's resources would seem less likely. Furthermore, the respiratory systems of $A$. vinelandii and $B$. natriegens, which have similar inhibitor characteristics, have been shown to be branched.

The oxidation of NADH and succinate by the particulate fraction of $C$. violaceum grown on complex medium, is relatively resistant to $\mathrm{CO}$ inhibition, although there is considerable inhibition at high $\mathrm{CO}$ concentrations (Fig. $2 b$ ). However, the oxidation of NADH and succinate by the particulate fraction of cultures grown on minimal medium is essentially insensitive to $\mathrm{CO}$. These data suggest that $\mathrm{CO}$ acts, but with relatively low efficiency, on the cyanide/azide-resistant pathway, and the lack of a $\mathrm{CO}$ inhibitory effect on the particulate fraction of cultures grown on minimal medium is due to electron flow occurring preferentially via the cyanide-sensitive pathway. Some increase in inhibition of NADH and succinate oxidation occurred when $\mathrm{CO}$ plus low $(100 \mu \mathrm{M})$ cyanide were added together, but the results were found to be somewhat variable, as was previously found for $B$. natriegens (Weston et al. 1974).

Hydroxamic acids act as specific inhibitors of the cyanide-resistant alternate oxidase of branched, mitochondrial respiratory systems (Schonbaum et al. 1971). Salicylhydroxamic acid (up to Io mM) had negligible effect on NADH or succinate oxidation by $C$. violaceum, grown on minimal or complex medium, when present either alone or in combination with cyanide, azide or $\mathrm{CO}$.

In view of the two respiratory pathways displayed by the particulate fraction derived from $C$. violaceum grown under conditions of low cyanide evolution, it might be expected that under these conditions the bacterium would synthesize a larger number of different cytochromes, especially the oxidases, than during growth under high-cyanide-evolving conditions, when only the cyanide-resistant pathway is present. Surprisingly, the reverse seems to be the case (Table 3); growth on complex medium yields bacteria with a particulate fraction containing cytochromes $a_{1}, d, c$ (CO-binding) and $o$ as the CO-binding cytochromes and hence possible oxidases, whereas the particulate fraction of cultures grown on minimal medium contains essentially only cytochromes $o$ and $c$ (CO-binding). The concentration of cytochrome $c$ (CO-binding) (plus cytochrome $o$ ) of the latter particulate fraction is double that of the former. In addition, while CO-binding is generally taken as an indication that a cytochrome is an oxidase, it could, perhaps, be functioning as an oxygenase or oxygen carrier, or the cytochrome may be denatured. It is therefore difficult to ascertain the exact roles of the different cytochromes without further data from kinetic and $\mathrm{CO}$-action spectra experiments, as well as a knowledge of the redox potentials of the cytochromes.

It is of interest that the larger portion of the CO-binding cytochrome $c$ occurs in the supernatant fractions of $C$. violaceum. Addition of supernatant fraction to particulate fraction did not result in any stimulation of oxidase activity. This could be due to sufficient cytochrome $c$ remaining on the membrane for maximal activity, the relative concentration of this cytochrome in the supernatant fraction being too low, it having no direct role in respiration, or to the cytochrome $c$ being inactive, perhaps through dislocation from the membrane. Studies on the supernatant-fraction, CO-binding cytochrome $c$ are complicated 
by the presence of lower concentrations of $b$-type cytochromes: the latter may be due to low concentrations of contaminating, non-sedimented, material.

Beneckea natriegens contains a high potential CO-binding cytochrome $c$ (Weston \& Knowles, 1973, 1974). This cytochrome is also located principally in the supernatant fraction from disrupted cells, and again respiration occurs almost exclusively in the particulate fraction. The bacterium also possesses a cyanide-resistant respiratory pathway (Weston et al. 1974). Methane- and methanol-oxidizing bacteria grown on methane or methanol synthesize a CO-binding cytochrome $c$ (also found in the supernatant fraction) as their major cytochrome component (Tongue et al. 1974). Marine pseudomonad в I 6 contains large quantities of a CO-binding, $c$-type cytochrome but no other CO-binding cytochromes (Knowles, Calcott \& MacLeod, 1974). Again, this cytochrome is located in the supernatant fraction of bacteria disrupted by sonication or in a French press. However, selective wall-stripping procedures have shown the CO-binding cytochrome $c$ to be located in the periplasmic space of BI 6 (Knowles et al. 1974), which suggests that the similar cytochromes observed in B. natriegens, the methylotrophs and $C$. violaceum may also occur in the periplasm rather than being soluble cytoplasmic enzymes. We have therefore done some preliminary experiments to determine the cellular location of the CO-binding cytochrome $c$ of $C$. violaceum. Sphaeroplasts of $C$. violaceum (grown on complex medium) were prepared by lysozyme-EDTA treatment of bacteria suspended in $0.9 \mathrm{M}$-sucrose. Assay of release of the cytoplasmic enzymes, isocitrate dehydrogenase and glutamate dehydrogenase, showed that there was little lysis (o to $12 \%$ ). However, 60 to $70 \%$ of the CO-binding cytochrome $c$, usually found in the supernatant fraction, was released, with essentially no release of cytochrome $b$ or other cytochromes. Spectral assay of the supernatant fraction of sonicates of sphaeroplasts showed a corresponding decrease in concentration of the CO-binding cytochrome $c$, and the ratio of cytochrome $c$ to cytochrome $b$ was about $I: I$, whereas the ratio found in the supernatant fraction derived from untreated bacteria was about 4: I (Table 3). Thus, we tentatively conclude that the CO-binding cytochrome $c$ of $C$. violaceum is periplasmic in origin. The cytochromes remaining in the supernatant fraction are presumably contaminating, non-sedimented, particulate fraction cytochromes, which would explain the presence of the cytochrome $b$ shoulder on the cytochrome $c$ peak (Figs. 6, 7) of the supernatant fraction derived from intact bacteria.

We are grateful to the Science Research Council for financial support. The dual wavelength spectrophotometer was purchased with the aid of a grant from The Royal Society.

\section{REFERENCES}

ACKrell, B. A. C. \& Jones, C. W. (1971). The respiratory system of Azotobacter vinelandii. I. Properties of phosphorylating respiratory membranes. European Journal of Biochemistry 20, 22-28.

ARIMA, K. \& OKA, T. (1965). Cyanide resistance in Achromobacter. I. Induced formation of cytochrome $a_{2}$ and its role in cyanide-resistant respiration. Journal of Bacteriology 90, 734-743.

BARTSCH, R. G. (1967). Spectroscopic properties of purified cytochromes of photosynthetic bacteria. In Bacterial Photosynthesis, pp. 475-494. Edited by H Gest, L. P. Vernon and A. San Pietro. Antioch, Ohio: Antioch Press.

Bauchop, T. \& ElsDen, S. R. (1960). The growth of micro-organisms in relation to their energy supply. Journal of General Microbiology 23, 457-469.

BeNDAll, D. S. \& BoNNER, W. D. (I97I). Cyanide-insensitive respiration in plant mitochondria. Plant Physiology 47, 236-245.

Chance, B. (1961). Cytochrome o. In Haematin Enzymes, pp. 433-435. Edited by J. E. Falk, R. Lemberg and R. K. Morton. Oxford, London, New York and Paris: Pergamon Press. 
DANIEL, R. M. (1970). The electron transport system of Acetobacter suboxydans with particular reference to cytochrome $o$. Biochimica et biophysica acta 216, 328-341.

DownIE, J. A. \& GARLAND, P. B. (1973). An antimycin A- and cyanide-resistant variant of Candida utilis arising during copper-limited growth. Biochemical Journal 134, I05I-I061.

EpsteIn, J. (1947). Estimation of microquantities of cyanide. Analytical Chemistry 19, 272-274.

Gel'man, N. S., Lukoyanova, M. A. \& Ostrovski, D. N. (1967). Respiration and Phosphorylation of Bacteria, pp. 140-142. New York: Plenum Press.

Gornall, A. G., BardaWill, C. S. \& David, M. M. (1949). Determination of serum proteins by means of the biuret reaction. Journal of Biological Chemistry 177, 751-763.

von JAGOw, G. \& KLINGENBerg, M. (1970). Pathways of hydrogen in mitochondria of Saccharomyces carlsbergensis. European Journal of Biochemistry 12, 583-592.

JONES, C. W. \& REDFEARN, E. R. (1966). Electron transport in Azobacter vinelandii. Biochimica et biophysica acta II3, 467-48I.

JONES, C. W. \& REDFEARn, E. R. (1967). The cytochrome system of Azobacter vinelandii. Biochimica et biophysica acta 143, 340-353.

Knowles, C. J., CalcotT, P. H. \& MacLeod, R. A. (1974). Periplasmic CO-binding $c$-type cytochrome in a marine bacterium. FEBS Letters 49, 78-83.

Lambowitz, A. M. \& Slayman, C. W. (197I). Cyanide-resistant respiration in Neurospora crassa. Journal of Bacteriology 108, 1087-1096.

McFeters, G. A., Wilson, D. F. \& Strobel, G. A. (1970). Cytochromes in a cyanide-resistant strain of Bacillus cereus. Canadian Journal of Microbiology 16, $122 \mathrm{I}-1226$.

MiCHAELS, R. \& CORPE, W. A. (1965). Cyanide formation by Chromobacterium violaceum. Journal of Bacteriology 89, 106-112.

MILLER, J. H. (1972). Experiments in Molecular Genetics, p. 431. Cold Spring Harbor: Cold Spring Harbor Laboratory.

PUDEK, M. R. \& BRAGG, P. D. (1974). Inhibition of the respiratory chain oxidases of Escherichia coli. Archives of Biochemistry and Biophysics 164, 682-693.

RAY, S. K. \& CRoss, G. A. M. (1972). Branched electron transport chain in Trypanosoma mega. Nature New Biology 237, I74-I 75 .

Schonbaum, G. R., Bonner, W. D., Storey, B. T. \& Bahr, J. T. (1971). Specific inhibition of the cyanideinsensitive respiratory pathway in plant mitochondria by hydroxamic acids. Plant Physiology 47, 124128.

SLATER, E. C. (1967). Application of inhibitors and uncouplers for a study of oxidative phosphorylation. Methods in Enzymology ro, 48-57.

SNEATH, P. H. A. (1966). Identification methods applied to Chromobacterium. In Identification Methods for Microbiologists, part A, pp. 15-20. Edited by B. M. Gibbs and F. A. Skinner. London and New York: Academic Press.

Tonge, G. M., Knowles, C. J., Harrison, D. E. F. \& Higgins, I. J. (1974). Metabolism of one carbon compounds: cytochromes of methane- and methanol-utilising bacteria. FEBS Letters 44, 106-I IO.

Weston, J. A., Collins, P. A. \& Knowles, C. J. (1974). The respiratory system of the marine bacterium Beneckea natriegens. II. Terminal branching of respiration to oxygen and resistance to inhibition by cyanide. Biochimica et biophysica acta 368, 148-157.

Weston, J. A. \& KNOWLes, C. J. (1973). A soluble CO-binding $c$-type cytochrome from the marine bacterium Beneckea natriegens. Biochimica et biophysica acta 305, I I-I 8 .

WeSTON, J. A. \& KNOWLES, C. J. (1974). The respiratory system of the marine bacterium Beneckea natriegens. I. Cytochrome composition. Biochimica et biophysica acta 333, 228-236. 